\title{
STUDY OF THE POTENTIAL ANTIULCEROUS ACTION OF HYDROALCOHOLIC EXTRACTS FROM PRUNELLA VULGARIS L. OF ROMANIAN ORIGIN
}

\author{
ALEXANDRA GROȘAN ${ }^{1}$, RUXANDRA ȘTEFĂNESCU ${ }^{2} *$, SIMONA GURZU ${ }^{3}$, DANIELA \\ LUCIA MUNTEAN $^{4}$, LAURIAN VLASE $^{5}$, CAMIL-EUGEN VARI ${ }^{1}$
}

\author{
${ }^{I}$ Department of Pharmacology and Clinical Pharmacy, Faculty of Pharmacy, “George Emil Palade” University of Medicine, \\ Pharmacy, Science, and Technology of Târgu Mureș, Romania \\ ${ }^{2}$ Department of Pharmacognosy and Phytotherapy, Faculty of Pharmacy, "George Emil Palade" University of Medicine, \\ Pharmacy, Science, and Technology of Târgu Mureș, Romania \\ ${ }^{3}$ Department of Pathology, "George Emil Palade" University of Medicine, Pharmacy, Science, and Technology of Târgu \\ Mureș, Romania \\ ${ }^{4}$ Department of Analytical Chemistry and Drug Analysis, Faculty of Pharmacy, "George Emil Palade” University of \\ Medicine, Pharmacy, Science, and Technology of Târgu Mureș, Romania \\ ${ }^{5}$ Department of Pharmaceutical Technology and Biopharmaceutics, "Iuliu Hațieganu” University of Medicine and \\ Pharmacy Cluj-Napoca, Romania
}

*corresponding author: ruxandra.stefanescu@umfst.ro

Manuscript received: March 2020

\begin{abstract}
Prunella vulgaris L. (Lamiaceae family) species is widespread throughout the world and the fruit-spike is used in folk medicine in many countries. The Romanian resource of Prunellae spica is poorly studied from a phytochemical and pharmacological point of view; accordingly, the present study aimed to evaluate the anti-ulcer action of a hydroalcoholic extract of this species with standardized polyphenol content. The extracts used were phytochemically characterized by the total polyphenol content (TPC) and by the determination of the constituents (phenol-carboxylic acids, flavonoids) by HPLC-MS/MS. Quantitative analysis showed the presence of flavonoids in glycosidic form in fairly large quantities (hyperoside, rutoside, isoquercitrin); on the other hand, smaller quantities of aglycones (quercetol, kaempferol, apigenin) were identified and quantified. Moreover, phenolcarboxylic acids, such as caftaric, ferulic, p-coumaric acid, were measured. Two types of doses (high dose $-50 \mathrm{mg} / \mathrm{kg}$ body weight (kgbw), respectively low dose $10 \mathrm{mg} / \mathrm{kgbw}$, values expressed in gallic acid equivalents) were administered preventively/curatively in rats with phenylbutazone-induced ulcer; ranitidine at $50 \mathrm{mg} / \mathrm{kgbw}$ was used as an activity control. Efficacy was quantified by measuring ulcer index, as well as by examination of gross features and histopathological changes. The hydroalcoholic extracts of Prunella vulgaris L. proved to have a dose-dependent antiulcerous action in curative treatment. As the titratable acidity is not decreased by the treatment, the effect is mediated by the prevention of oxidative inflammation of the mucosa. Histopathological results confirmed these in vivo results. Prunellae spica of Romanian origin is a plant resource rich in polyphenols that has shown protective effects on nonsteroidal anti-inflammatory drugs (NSAID)-related gastric ulcer. The observed effects are dose-dependent, probably mediated by inhibition of oxidative stress in the mucosa and promotion of regeneration processes.
\end{abstract}

\section{Rezumat}

Specia Prunella vulgaris L. (Lamiaceae) este răspândită în întreaga lume, iar fructul este folosit în medicina populară în multe țări. Resursa românească de Prunellae spica este puțin studiată din punct de vedere fitochimic și farmacologic, în consecință, prezentul studiu a avut ca scop evaluarea acțiunii anti-ulceroase a unui extract hidroalcoolic din această specie cu conţinut standardizat de polifenoli. Extractele utilizate au fost caracterizate fitochimic prin conținutul total de polifenoli (TPC) și prin determinarea constituenților (acizi fenol-carboxilici, flavonoizi) prin HPLC-MS/MS. Analiza cantitativă a arătat prezența flavonoidelor în formă glicozidică în cantități mari (hiperozid, rutozid, izoquercitrin), pe de altă parte, au fost identificate şi cuantificate cantități mai mici de agliconi (quercetol, kaempferol, apigenină). Mai mult, au fost cuantificați acizii fenol-carboxilici, ca acidul caftaric, ferulic, p-cumaric. Două tipuri de doze (doză mare - $50 \mathrm{mg} / \mathrm{kgc}$, respectiv doză mică $10 \mathrm{mg} / \mathrm{kgc}$, valori exprimate în echivalenți de acid galic) au fost administrate preventiv/curativ la șobolani cu ulcer indus de fenilbutazonă; ranitidină $50 \mathrm{mg} / \mathrm{kgc}$ a fost utilizată ca referinţă. Eficacitatea a fost cuantificată prin determinarea indicelui ulcerului, precum şi prin examinarea caracteristicilor brute și a modificărilor histopatologice. Extractele hidroalcoolice de Prunella vulgaris L. s-au dovedit a avea o acțiune antiulceroasă dependentă de doză în tratamentul curativ. Rezultatele histopatologice au confirmat aceste rezultate in vivo. Prunellae spica de origine română este o resursă vegetală bogată în polifenoli care a demonstrat efecte protectoare asupra ulcerului gastric legat de medicamentele antiinflamatoare nesteroidiene (AINS); efectele observate sunt dependente de doză, probabil mediate de inhibarea stresului oxidativ în mucoasă și promovarea proceselor de regenerare.

Keywords: Prunellae spica, gastric ulcer, HPLC, polyphenols 


\section{Introduction}

Peptic ulcer is a common condition caused by environmental factors (consumption of spicy food, alcohol abuse, coffee, smoking, stress) [17, 38, 48], non-compliance with meal times, co-infection with Helicobacter pylori, as well as the abuse of drugs involved in iatrogenic aggression on the gastric mucosa (nonsteroidal anti-inflammatory drugs - NSAIDs, corticosteroids, etc.). The treatment relies on therapeutic classes such as proton pump inhibitors, antihistamines blocking $\mathrm{H}_{2}$ receptors which have anti-secretory action and can cause drug interactions (inhibition of CYP2C9, 2C19 for omeprazole, CYP3A4 for certain antihistamines H2 drugs) [25, 26]. Drugs with protective action on the gastric layer are used rather infrequently (prostaglandin analogues, carbenoxolone, sucralfate). Herbal medicine for gastric ulcers (preventive and/or curative actions) uses products containing mucilage (carrageenan, Malvae flos, Plantago herba) or glycyrrhetinic acid derivatives (Liquiritiae radix) whose structure was the basis of conception of carbenoxolone $[9,22]$.

There are currently few studies on the antiulcer action of flavonoids (luteolin, hyperoside) [4, 16] polyphenols (paeniflorine, albiflorine), and phenolcarboxylic acids (chlorogenic acid, caffeic acid, rosmarinic acid) $[3,43,56]$. To quantify these effects on the decrease in gastric secretion and the increase in defence factors (endogenous prostaglandins), numerous studies have evaluated extracts standardized in phytocompounds [28]; thus, various methods of producing experimental ulcers have been developed - by ligation of the pylorus, by administration of reserpine, indomethacin or $\mathrm{HCl} /$ ethyl alcohol or by induction of stress ulcer; in all cases, the experimental animal used is preferably the rat.

The present study aims to evaluate the antiulcerous potential of the hydroalcoholic extract of the spiciform inflorescence of the species Prunella vulgaris L. due to the high content of active ingredients [5, 32, 39, 40, 45-47, 52]. Prunella vulgaris L. is a perennial species widespread in the Romanian flora. Although, the species is officinal in the $10^{\text {th }}$ edition of the European Pharmacopoeia (monograph Common selfheal fruit-spike Prunellae spica) [15], it is hardly used in Romanian folk medicine. Consequently, phytochemical and phytopharmacological studies are insufficient to characterize native species. The officinalis species contain triterpene saponosides (ursolic acid, oleanolic acid), but studies in various parts of the world also indicate a high content of polyphenols and phenolcarboxylic acids.

The content of these active ingredients in Prunella species depends on the stage of development of the plant (with a maximum at the end of the flowering period) and its habitat [31]. However, the existing data in the literature concerning the chemical composition of the species Prunella vulgaris L. mainly refer to the product of Chinese origin.

In the absence of published works on the species in Romania, the data reported by Golembiovka OI and Şahin S et al. could serve as a reference, because the soil and climate conditions existing in Romania are comparable (the climate is temperate continental similar to that of Ukraine, but harsher than in Turkey) [20, 51]. The authors mentioned having established a largely similar phytochemical profile, characterized by the presence of phenolic acids (rosmarinic acid, caffeic acid, ferulic acid, chlorogenic acid, protocatechuic acid) and flavonoids (rutoside, quercetol); the quantified compounds are in variable proportions depending on the plant parts used and the solvent used in the extraction.

According to the literature, polyphenolic compounds have a gastro-protective effect by increasing the production of mucus, by suppressing the activity of neutrophils and pro-inflammatory cytokines [43, 44]. The present study aims to supplement the phytopharmacological data missing in the case of species of Romanian origin.

\section{Materials and Methods}

\section{Obtaining hydroalcoholic extracts}

Prunella vulgaris L. was collected in Mureș County, Romania and a specimen was archived as a voucher sample (PV-L-19) at the Department of Pharmacognosy and Phytotherapy, George Emil Palade University of Medicine, Pharmacy, Science and Technology of Târgu Mureș, Romania. The ground vegetable product (Prunellae spica) was extracted with the appropriate solvent (methanol/water $=70 / 30 \mathrm{v} / \mathrm{v}$ ) on an ultrasonic bath at $40^{\circ} \mathrm{C}$ for 60 minutes. After cooling, the extract was filtered and the methanol was removed in a reflux apparatus at $40^{\circ} \mathrm{C}$ to protect the active ingredients which are thermo-labile. The obtained product was maintained in optimal conditions until its administration (aqueous suspension, and the reconstitution was carried out ex temporae by suspending it in freshly prepared distilled water).

Chemicals. Solvents. Drugs

All of the used substances were purchased from approved commercial sources: phenylbutazone - Nantong Jinghua Pharm (Nantong, China), methanol (used for obtaining the hydroalcoholic extract) - Poulten \& Graf GmbH (Wertheim, Germany), ranitidine Medochemie Ltd (Limassol, Cyprus), phenol red solution - Sigma-Aldrich (Darmstadt, Germany).

Standardization of extracts

Analysis of polyphenolic content was assessed by TPC method (total polyphenolic content) and by HPLC/MS/MS analysis.

Total polyphenolic content

The total polyphenolic content of the obtained extract was determined by the TPC method using a spectro- 
photometric method with Folin-Ciocâlteu reagent expressed in mg GAE/1 $\mathrm{g}$ dry vegetable product (gallic acid equivalent) as described by Singleton VL et al. [50]. We extracted $5 \mathrm{~g}$ of plant product with $50 \mathrm{~mL}$ of solvent, then $0.5 \mathrm{~mL}$ of the sample was diluted to $10 \mathrm{~mL}$, the diluted sample being used in the determinations. The preparation of standards and samples for analysis was carried out in dark-coloured bottles, protected from light, using a methodology similar to Abdykerimova et al. [2].

Thus, $40 \mu \mathrm{L}$ of sample or standard solution were diluted with $3160 \mu \mathrm{L}$ of distilled water; then $200 \mu \mathrm{L}$ of Folin Cocâlteu reagent and $600 \mu \mathrm{L}$ of $20 \% \mathrm{NaHCO}_{3}$ were added. After shaking and then storing it in the dark for 30 minutes, the absorbance of the samples was read at $765 \mathrm{~nm}$. A fitting curve using gallic acid as standard was freshly prepared in the same conditions on the day of analysis. We used five points for the fitting curve (from the gallic acid stock solution of $0.5 \mathrm{~g} / 100 \mathrm{~mL}$ was removed 1, 3, 5, 7 and $10 \mathrm{~mL}$ and diluted to $100 \mathrm{~mL}$ with distilled water. Subsequently, the above described procedure was performed resulting in the final concentrations per samples 0.002, 0.006, $0.01,0.14$ and $0.02 \mathrm{mg}$ ). The obtained determination coefficient was $\mathrm{R}^{2}=0.9865$.

The determination of the total polyphenolic content of the extracts was used to calculate the doses administered to the experimental animals (daily dose and total cumulative dose, relative to the duration of treatment).

\section{HPLC/MS/MS analysis}

For the qualitative and quantitative analysis of the polyphenols in the plant extract, high performance liquid chromatography coupled with mass spectrometry (HPLC-MS) was used, according to the method described by Vlase et al. [8, 33, 35, 41]. Quantitative analytical determinations were performed on an HPLC/MS/MS system with a binary pump. Collision energy was 1.2 $\mathrm{V}$ and fragmentation time $100 \mathrm{~ms}$. Separation was performed on a Zorbax SB-C18 reverse phase chromatographic column, $100 \mathrm{~mm}$ x $3.0 \mathrm{~mm}$ i.d., $3.5 \mu \mathrm{m}$ (Agilent, USA). The mass spectrometer was an Agilent Ion Trap 1100 SL (Santa Clara, CA, USA) equipped with electrospray ionization (ESI) in negative regime (capillary $+3000 \mathrm{~V}$ ), 60 psi nebulizer, gas dry nitrogen at $12 \mathrm{~L} /$ minute, dry gas temperature $360^{\circ} \mathrm{C}$. Characteristics of the separation process: elution solvents: mixture of methanol:acetic acid $0.1 \% \mathrm{v} / \mathrm{v}$ as mobile phase; elution - linear gradient starting with $5 \%$ methanol and ending at $42 \%$ methanol at 35 minutes; working temperature: $48^{\circ} \mathrm{C}$; flow rate: 1 $\mathrm{mL} / \mathrm{min}$; injection volume: $5 \mu \mathrm{L}$.

Chromatographic data were processed using ChemStation and software for acquisition: IonTrap Control manufactured by Brucker Daltonics Inc., software for analysis: Data Analysis manufactured by Brucker $[8,33,35,41]$.

\section{Animals}

Wistar rats (300 - $330 \mathrm{~g})$ from the Animal facilities of "George Emil Palade" University of Medicine, Pharmacy, Science, and Technology of Târgu Mureș, Romania were used. Throughout the experiment, the animals were maintained under standard conditions of temperature $\left(22 \pm 2^{\circ} \mathrm{C}\right)$ and humidity $(45-80 \%)$ with a day/night cycle of 12 hours. The animals received food corresponding to the species and had unlimited access to water and food. The accommodation and care of the animals also took into account the needs and characteristics of the species and hygiene standards. Each group included 10 animals, except for the control group which comprised 15 animals, 5 of which were euthanized shortly after ulcer induction in order to verify that the gastric lesions are present. All experimental procedures were performed in accordance with international guidelines for ethical research established and approved in advance by the Ethics Committee of "George Emil Palade" University of Medicine, Pharmacy, Science, and Technology of Târgu Mureș, Romania.

\section{Ulcer induction method}

For the induction of quantifiable gastric lesions, the phenylbutazone ulcer induction method was used. It was administered intraperitoneally in a single dose $(150 \mathrm{mg} / \mathrm{kg}$ body weight (kgbw), the ulcerogenic effect was mediated by non-selective inhibition of cyclooxygenases. The severity of ulcerative lesions was quantified by two methods, as follows: a qualitative one - the macroscopic score that assesses the severity of haemorrhagic lesions ( 0 - quasi-normal appearance; 1 - minor lesions (punctiform); 2 - single or rare lesions; 3 - multiple lesions (frequent haemorrhagic spots and rare ulcers); 4 - lesions of high severity; 5 - mucosa affected in totality and/ or perforations). The images were acquired using a professional camera (Nikon camera f22, ISO 600, $60 \mathrm{~mm}$ macro lens, flash) and stored until processing. The area of gastric haemorrhagic lesions was quantified by digitizing images (in uncompressed format, at a resolution of $1600 \times 1200 \mathrm{dpi}$, and a scale of 1:1 of the actual size, using the enhancement, segmentation, and analysis modules from the Scion Image software), transforming into gray tones and measurement of the haemorrhagic area by colour code (Figure 1).

The areas of the lesions were measured in square pixels and were divided by the total area of the mucosa, by determining the percentage of the affected area. Ulcer index (UI) was determined based on the ratio of the area of the ulcerous lesions to the total area of the glandular mucosa and forestomach for each animal in the group based on the following formula:

$$
U I(\%)=\frac{\sum(\text { ulcerated area })}{\text { total area of gastric mucosa }} \cdot 100 .
$$



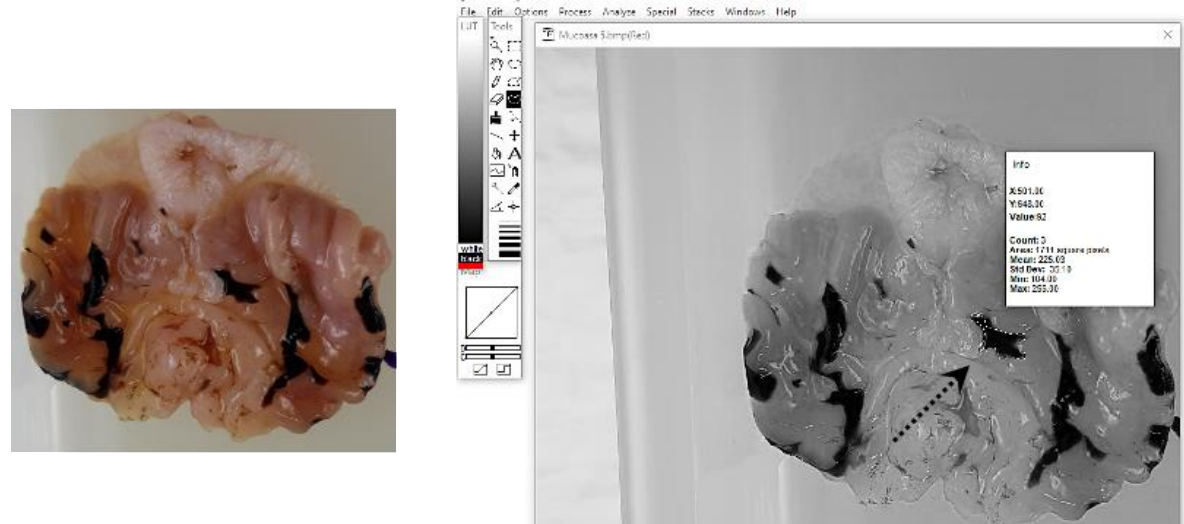

Figure 1.

Image processing in the Scion Image software for estimating the ulcer area (arrow - measuring the surface of the selected area in square pixels)

The estimation of the antiulcer action (degree of inhibition of lesions caused by the ulcer inducing agent, in the degree of protection in both preventive and curative treatment) was performed for each type of therapeutic intervention (medication, dose, duration of treatment) by comparison with the control group as follows:

$\%$ of Ulcer inhibition $=\frac{U I_{\text {control }}-U I_{\text {test }}}{U I_{\text {control }}} \cdot 100 .$.
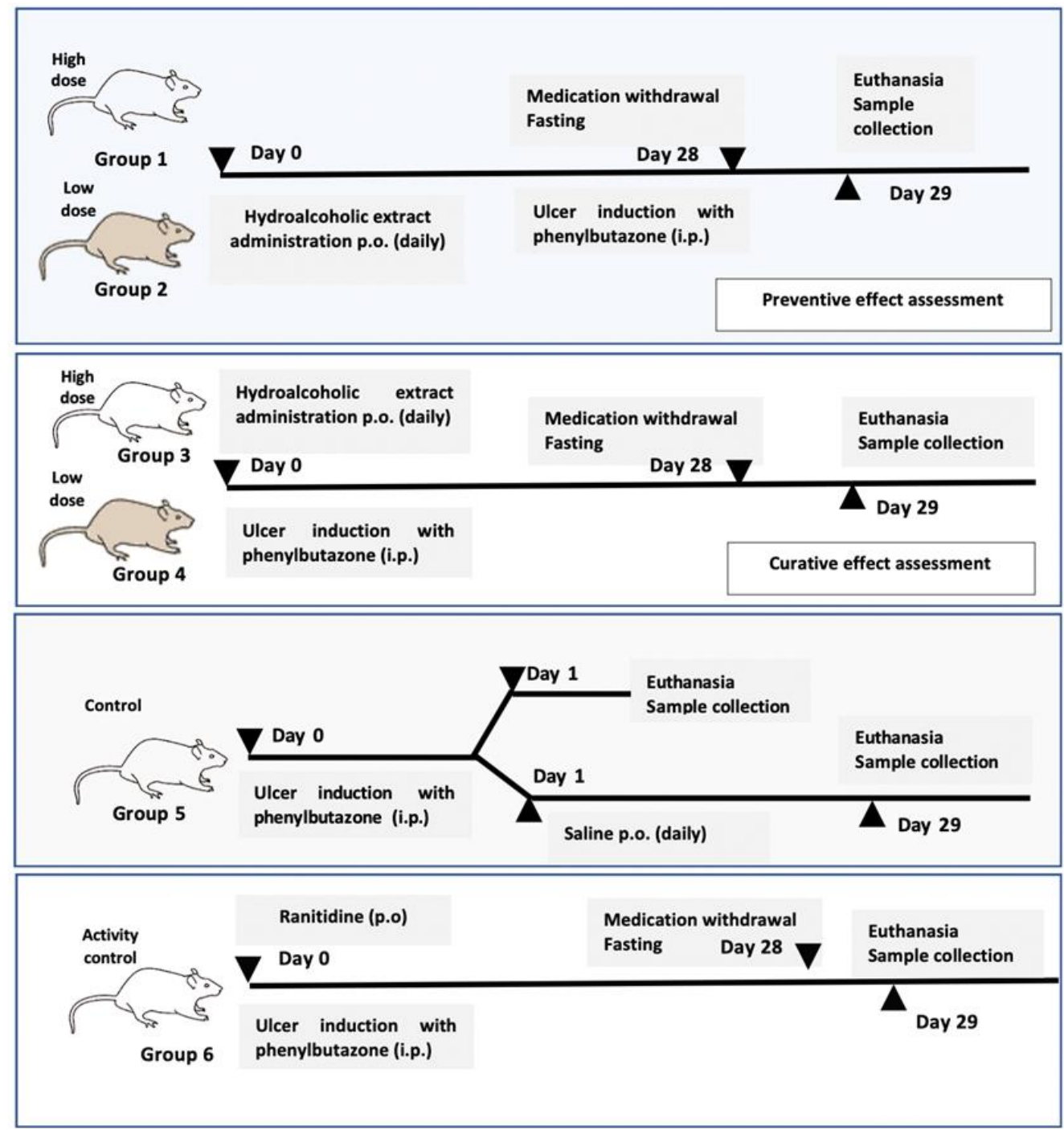

Figure 2.

Experimental design and activity planning (p.o. - oral administration; i.p. - intraperitoneal administration) 
Group 1 (preventive) - coded PV1 high dose administration of hydroalcoholic extract of Prunellae spica (equivalent to $50 \mathrm{mg}$ total polyphenols $/ \mathrm{kgbw}$, expressed in gallic acid) by gavage, for 4 weeks, followed by ulcer induction by phenylbutazone; after 24 hours, the animals were anesthetized by inhalation of isoflurane and euthanized by cervical dislocation, followed by the opening of the abdomen through a midline incision to remove the stomach after ligation of the pylorus and cardia; the stomach was incised along the line of the great curvature, and the gastric contents (when available) were removed, placed in Eppendorf tubes and centrifuged at $5000 \mathrm{rpm}$ for 10 minutes. An amount of $200 \mu \mathrm{L}$ of supernatant was taken and diluted with distilled water; subsequent samples of it were used to determine acidity, using phenol red as indicator.

Group 2 (preventive) - coded as PV2 low dose administration of hydroalcoholic extract of Prunellae spica (equivalent to $10 \mathrm{mg}$ total polyphenols $/ \mathrm{kgbw}$, expressed in gallic acid), by gavage, for 4 weeks; next, the procedure was identical to that performed on the previous group.

Group 3 (curative) - coded as CV 1 high dose - after induction of ulcer by phenylbutazone, the animals were treated daily by gavage with hydroalcoholic extract of Prunella spica (high dose - equivalent to $50 \mathrm{mg}$ total polyphenols/kgbw, expressed as gallic acid) for 4 weeks; subsequently, the procedure was identical to the one described above.

Group 4 (curative) - CV 2 low dose - the procedure was identical to that of group 3, except for the dose used (low dose - the equivalent of $10 \mathrm{mg}$ total polyphenols/kgbw, expressed in gallic acid).

Group 5 - coded as Control (15 animals/group) - a gastric ulcer was induced with a single dose of phenylbutazone $150 \mathrm{mg} / \mathrm{kgbw}$ intraperitoneally; 5 of the animals in this group were slaughtered after 24 hours to demonstrate the occurrence of ulcerative lesions caused by drugs (to validate the ulcer induction method in the proposed animal model); the remaining animals (10/group, as in the other groups) received an equivalent volume of saline as the animals in the preceding groups for 4 weeks (for an equivalent procedure, taking into account in particular that the handling, restraint, and feeding of the animals induce stress and can influence the results of this type of experiment);

Group 6 - activity control - coded as RAN - received ranitidine $50 \mathrm{mg} / \mathrm{kgbw}$ for 28 days, then phenylbutazone as an ulcerogenic agent, as well as the other groups, after which they were sacrificed and analysed as in the previous cases.
A diagram of the experimental protocol (procedures, drugs) is presented in Figure 2.

Microscopic analysis

For the histological assessment, stomach specimens from any animals were opened along the larger curvature, washed, and fixed in $10 \%$ neutral formaldehyde for 24 - 48 hours. After carefully grossing, representative tissue was included in paraffin blocks which were subsequently sectioned with the microtome at $5 \mu \mathrm{m}$. Two pathologists performed a blinded evaluation of the severity of the gastric injuries on haematoxylineosin slides. The qualitative descriptors firstly involved the depth of injuries. They were classified as superficial erosions (acute ulceration of the foveolar layer), deep erosions (injuries of the foveolar and glandular layer), and acute peptic ulcers (involvement of the mucosa and muscularis mucosae). Presence or absence of haemorrhage and inflammation was also counted.

Statistical analysis

The experimental results were statistically processed using the GraphPad Prism 8 software. Quantitative data are presented as mean \pm standard error. One-way ANOVA followed by Tukey's post-hoc test was applied to assess statistical significance of the results (ulcer index, titratable acidity). The nonparametric Kruskal-Wallis test, followed by Dunn's post hoc multiple comparisons test was used to compare the differences between groups for the macroscopic ulceration score. The significance threshold was set at $\mathrm{p}<0.05$.

\section{Results and Discussion}

\section{Phytochemical assay}

The hydroalcoholic extract used in the pharmacological experiments contained polyphenols (expressed in gallic acid equivalents relative to the dried plant product used for extraction - Prunellae spica) of $36.44 \mathrm{~g}$ GAE/g. Of this total polyphenol, by HPLC/MS/MS analysis, several polyphenols (flavonoids, phenolcarboxylic acids) were highlighted, the data being presented in Table I, and a representative chromatogram for the quantification of polyphenols in the hydroalcoholic extract is presented in Figure 3. The target analysis mode was made, based on positive compounds identification by using reference standards (so the specific retention time and MS spectra were already known). When analysing elution order we can state that the tendency is to elute firstly the more hydrophilic compounds because the chromatographic column is hydrophobic (C18); as such, just as classes, phenolcarboxylic acids elute first, followed by heterosides, only then heteroside aglycons which are the most hydrophobic. 
Quantification of polyphenols in hydroalcoholic extract of Prunellae spica

\begin{tabular}{|c|c|c|c|c|c|}
\hline $\begin{array}{l}\text { Identified } \\
\text { compound }\end{array}$ & $\begin{array}{l}\text { Identified } \\
\text { by UV/MS }\end{array}$ & $\begin{array}{l}\text { MS analysis } \\
\text { mode }\end{array}$ & $\begin{array}{l}\text { Retention } \\
\text { time (min) }\end{array}$ & $\begin{array}{l}\text { Specific ions for identification/ } \\
{[\mathrm{M}-\mathrm{H}] \text { ion }>\text { ions from spectra }}\end{array}$ & $\begin{array}{c}\text { Amount }(\mu \mathrm{g} / \mathrm{g} \text { of } \mathrm{dry} \\
\text { plant product) }\end{array}$ \\
\hline Caftaric acid & yes & MRM & 2.10 & $311>148.6,178.6$ & 8.66 \\
\hline Gentisic acid & no/yes & MRM & 2.15 & $153>108.7$ & - \\
\hline Caffeic acid & no/yes & MRM & 5.6 & $179.4>134,7$ & - \\
\hline Chlorogenic acid & no/yes & MRM & 5.6 & $353.5>178.7,190.7$ & - \\
\hline p-Coumaric acid & yes & MRM & 8.7 & $163>118.7$ & 3.10 \\
\hline Ferulic acid & yes & MRM & 12.2 & $193.2>133.7,148.7,177.6$ & 4.17 \\
\hline Hyperoside & yes & auto MS & 18.6 & $463>254.9,270.9,300.7$ & 62.95 \\
\hline Isoquercitrin & yes & auto MS & 19.6 & $463>254.9,270.9,300.7,342.8$ & 95.30 \\
\hline Rutoside & yes & auto MS & 20.2 & $609.1>254.9,270.9,300.7,342.8$ & 268.72 \\
\hline Quercitrin & yes & auto MS & 23.0 & $447.1>178.8,300.7$ & 7.28 \\
\hline Quercetol & yes & auto MS & 26.8 & $301>150.6,178.6,272.7$ & 2.66 \\
\hline Kaempferol & yes & auto MS & 31.6 & $285>150.6,256.7$ & 3.71 \\
\hline Apigenin & yes & auto MS & 33.1 & $269.2>148.6,150.6,224.7,226.7$ & 5.28 \\
\hline
\end{tabular}

MRM (multiple reaction monitoring) - technique based on selection of a substance specific ion (used for phenol-carboxylic acids); auto MS - technique based on automated real-time MS/MS analysis of the sample that utilizes the best fragmentation information from a selection of prominent ions to be captured (used for all other polyphenolic compounds)

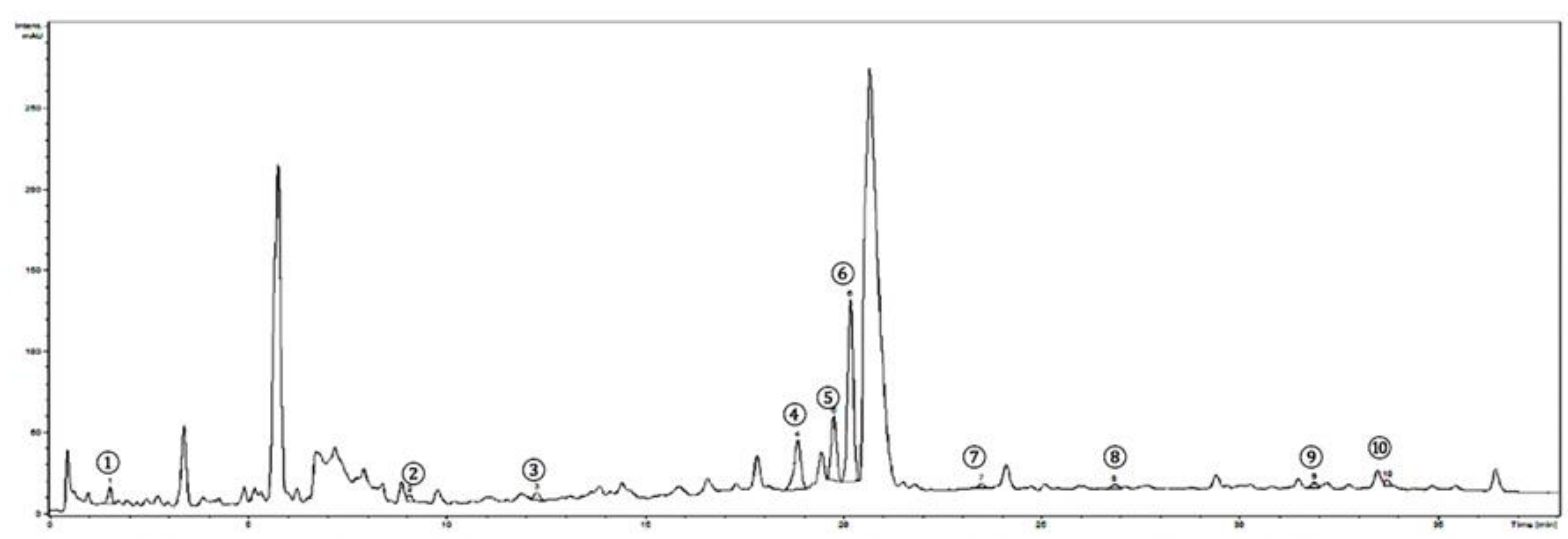

Figure 3.

Chromatogram of the hydroalcoholic extract of Prunellae spica

( 1 - caftaric acid, 2 - p-coumaric acid, 3 - ferulic acid, 4 - hyperozide, 5 - isoquercitrin, 6 - rutoside, 7 - quercitrin, 8 - quercetol, 9 - kaempferol, 10 - apigenin)

Macroscopic analysis of ulcerative lesions

The ulcer lesions of each group were quantified by determining the ulcer index value (UI\%). The percentage value of the UI (\%) and the macroscopic score, the volume of the gastric contents and the titratable acidity are presented in Table II; none of the extracts, regardless of the administered dose, influenced titratable acidity. The extracts used do not have an anti-ulcer effect in preventive treatment (they do not influence the hydro- chloric aggression induced by phenylbutazone), but they have a favourable effect over time, promoting the dose-related recovery of the mucosa in curative treatment. The gastro-protective effect of CV1 (high dose) and CV2 (low dose) measured by diminution of ulcerative lesions were $51.34 \%$ and $42.0 \%$; however, this effect is much lower in comparison to ranitidine (71.53\%).

Table II

Effect of treatments on quantitative descriptors of ulcer lesions - macroscopic score, ulcer index (mean \pm standard deviation (SD))

\begin{tabular}{lccc}
\hline \multicolumn{1}{c}{ Treatment } & Ulcer index $($ UI\%) & Macroscopic score & Titratable acidity $(\mathrm{mEq} / \mathrm{L})$ \\
\hline PV1 high dose & $20.51 \pm 8.43$ & $4.10 \pm 0.99^{\# \dagger}$ & $39.01 \pm 10.99$ \\
PV2 low dose & $24.34 \pm 9.12$ & $4.10 \pm 0.74^{\# \dagger}$ & $39.19 \pm 7.63$ \\
CV1 high dose & $15.69 \pm 8.74^{\mathrm{a}}$ & $2.40 \pm 0.52^{*}$ & $37.53 \pm 5.03$ \\
CV2 low dose & $18.69 \pm 7.29$ & $3.30 \pm 1.06$ & $43.06 \pm 10.83$ \\
Control & $32.25 \pm 18.50$ & $4.20 \pm 0.63$ & $41.0 \pm 12.6$ \\
RAN & $9.18 \pm 4.80^{\mathrm{b}}$ & $1.20 \pm 1.03^{* *}$ & $24.59 \pm 12.74^{*}$ \\
\hline
\end{tabular}

${ }^{\mathrm{a}} \mathrm{p}<0.01$ (vs. Control); ${ }^{\mathrm{b}} \mathrm{p}<0.0001$ (vs. Control); ${ }^{*} \mathrm{p}<0.05,{ }^{* *} \mathrm{p}<0.0001$ (vs. Control); ${ }^{*} \mathrm{p}<0.001$ (vs. RAN); ${ }^{\dagger} \mathrm{p}<0.05$ (vs. CV1 high dose); ${ }^{\mathrm{t}} \mathrm{p}<0.05$ (vs. Control) 


\section{Microscopic examination}

Microscopic examination of stomach specimens revealed a quasi-normal appearance of the regenerated mucosa of the ranitidine-treated group. In the case of the control group, multiple deep erosions, with injuries of the foveolar and glandular layer, were associated with large haemorrhages and severe inflammation. In the case of groups treated preventively with hydroalcoholic extract of Prunellae spica (PV1 high dose and PV2 low dose), although erosions were emphasized, they did not present large haemorrhagic areas. Moreover, if haemorrhages occurred, they were limited to the foveolar layer and were seen only in the low dose group (PV2). The groups that received curative treatment with hydroalcoholic extract of Prunellae spica (CV1 high dose and CV2 low dose) showed patchy regeneration of the mucosa, but dysplasia of the glandular layer was highlighted to associate inflammation. Dysplasia of the glandular layer was seen in animals which received curative treatment with high dose hydroalcoholic extract (CV1). Figure 4 displays representative microscopic images of all of the described lesions.
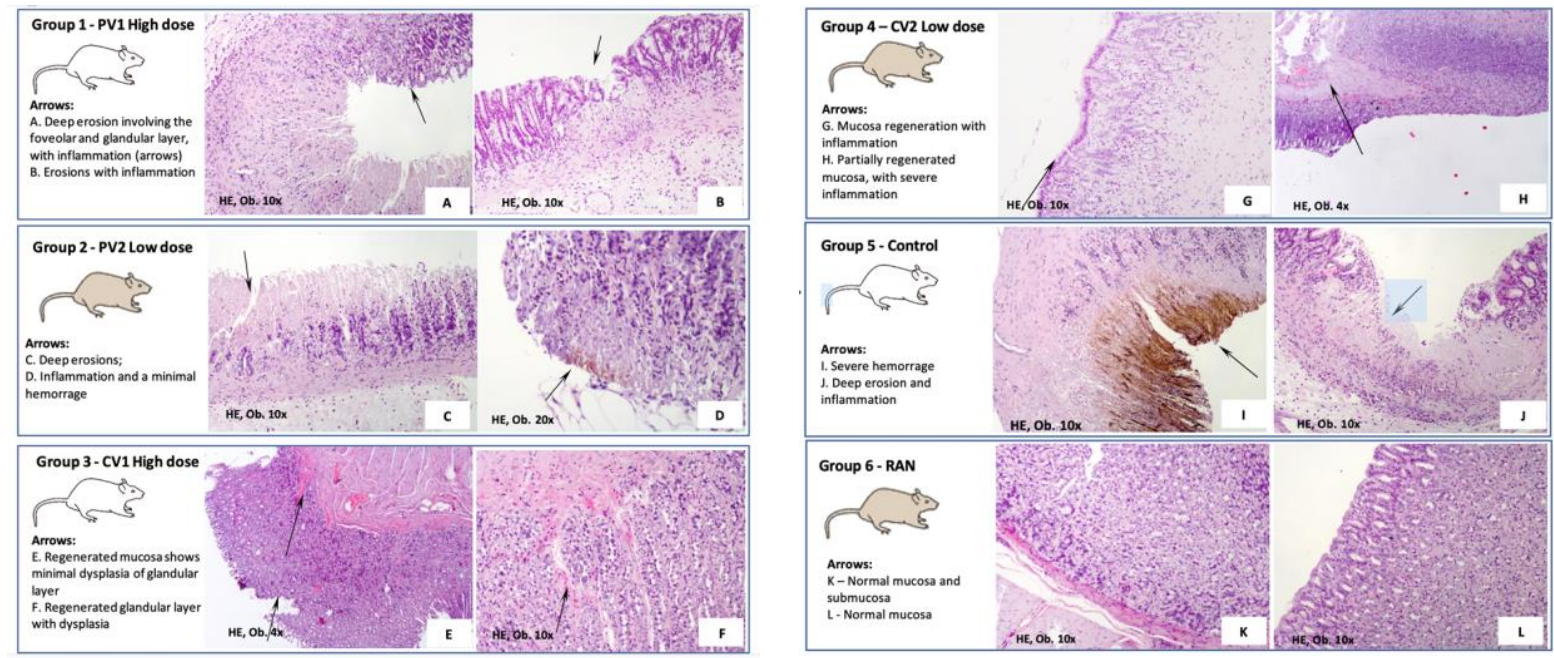

Figure 4.

Representative images of ulcers and associated lesions in the studied groups

There are many synthetic anti-ulcer drugs on the pharmaceutical market, but their use over a long period can lead to several side effects. Phytochemical compounds can be an alternative or their combination with synthetic substances for a synergistic action. The phytocompounds used in traditional medicine which contain active principles as protectors of the gastric mucosa belong to the different classes: mucilages (polysaccharides), sterols (derivatives of glycyrrhetinic acid) and, in particular, polyphenols which represent molecules with strong therapeutic interest. The studied extracts contain many substances belonging to the latter class (flavonoids, phenol-carboxylic acids). In addition to the saponoside content [15], Prunellae spica is a rich source of polyphenols (flavonoids, phenol-carboxylic acids) and is widely distributed in the spontaneous flora.

The Romanian plant product is rich in total polyphenols and we can emphasize the presence of phenol-carboxylic acids in large quantities, as well as glycosidic flavonoids (hyperoside, rutoside, quercitrine) and, to a lesser extent, aglycones (quercetol, apigenin, kaempferol). The results obtained by our team are comparable both qualitatively and quantitatively to those reported by researchers from the nearby geographic area (Ukraine, Turkey). They quantified the polyphenolic content of the same species by HPLC methods with detection of arrays of photodiodes. In the plant originating in the Ukrainian Carpathians, the authors found several phenol-carboxylic acids (protocatechuic, rosmarinic, chlorogenic, caffeic and ferulic acids), flavonoids (in particular the glycosides of apigenin and luteolin), as well as other phytotherapeutic compounds of interest (proanthocyanidins, catechins and their derivatives) [20]. The Turkish team analyzed the phytochemical profile of 4 Prunella species (Prunella vulgaris L., Prunella laciniata (L.) L., Prunella grandiflora L., Prunella orientalis Bornm.). They calculated the phenol-carboxylic acid content (rosmarinic acid, caffeic acid, ferulic acid, chlorogenic acid, protocatechuic acid) and flavonoids (rutoside, quercetol) and optimized the extraction process [51].

In a recent review, Wang SJ et al. systematized the data concerning the phytochemical composition of the species Prunella vulgaris L. According to the data collected, Prunella vulgaris L. contains approx. 200 compounds, their extraction being different depending on the solvent used: the aqueous extracts mainly contain polyphenols of the phenylpropanoid type (in particular rosmarinic acid and its derivatives, but also other phenol-carboxylic acids such as pcoumaric acid and caffeic acid) as well as carbohydrates (in particular monosaccharides - rhamnose, glucose, xylose); ethanolic extracts contain flavonoids 
(rutoside and hyperoside being the main compounds, but other quercetol glycosides are present, as well as small amounts of luteolin, homoorinetine) and triterpene compounds (especially ursolic and oleanolic acids). Other compounds are in too small quantities to make the extraction profitable (sterols, coumarins, long chain fatty acids, volatile oil, vitamins, proteins, alkaloids) [53]. The triterpene compounds (ursolic acid, oleanolic acid, betulin) present in Prunella vulgaris $\mathrm{L}$ also have an antineoplastic potential, demonstrated in vitro on cell lines of murine melanoma [19].

Another team of Chinese researchers quantified 4 phenol-carboxylic acids using an HPLC-ESI-MS/MS method for the screening of potential antineoplastic compounds in breast cancer (Yang A et al.): protocatechuic, caffeic, rosmarinic acids and protocatechualdehyde. The study did not analyse the other polyphenols (flavonoids) present [54]. Previously, Ba Y and Wang Y (2017), using an HPLC-UV method with DAD detector, quantified caffeic and chlorogenic acids in Prunella vulgaris L. in order to study their antiproliferative effect on cancer cells of the thyroid (K1) [6]. Instead, in the plant of Romanian origin, caffeic and chlorogenic acids could be identified by mass spectrometry, but not quantified; on the other hand, other compounds of the same class are predominant (caftaric, p-coumaric, and ferulic acids).

Liu $\mathbf{J}$ et al. quantified 10 antioxidant compounds of Prunella vulgaris L. which were studied to inhibit the proliferation of the A549 cell line by the MTT method. For this purpose, they used an HPLC-UV method coupled with MS identification, and the compounds identified were phenol-carboxylic acids (caffeic and rosmarinic acids), flavonoids (quercetol, hesperidin, luteolin), anthraquinones (rhein), and triterpenes (ursolic, oleoanolic, corosolic acids and oleanolic acid 3-O-glucuronide). The total content of the 10 compounds varied between 1.05 and $2.9 \mathrm{mg} / \mathrm{g}$ fresh plant depending on the geographical area, but, in all cases, the predominant compound was quercetol [30]. Contrary to these results, in our determinations, rutoside was the predominantly identified polyphenolic compound.

Although longtime known and widely contained in plant products, polyphenols are reconsidered as model molecules for the design of compounds whose mechanism inhibits inflammatory, apoptotic and/or necrotic processes by preventing the formation of free radicals. The proposed mechanisms for antioxidant action are the prevention of the free-radical chain reaction involved in the formation of reactive oxygen species, the chelating capacity of metals, the increase in the amount of reduced glutathione, and the potentiation of the catalytic action of enzymes which act as trappers (catalase, superoxide dismutase). All these mechanisms serve as a shield against oxidative attacks in the gastric mucosa [18].
The antioxidant effect of flavonoids and phenolcarboxylic acids responsible for the decrease in markers of oxidative stress (MDA - malonyldialdehyde) and the increase in the capacity of enzymatic and nonenzymatic antioxidants (catalase, superoxide dismutase, glutathione peroxidase, high glutathione) has been demonstrated for the polyphenolic extract of Cuphea ignea and of some Salvia species [23, 36]. These effects of plant polyphenols have been described by Farzaei MH et al. in a systematic analysis concerning the inverse relationship between the intake of polyphenols and peptic ulcer: capture of free radicals, increased synthesis of glutathione and inhibition of the intracellular inflammatory pathway (MAPK - protein kinase activated by a mitogen, ERK - regulated extracellular kinase, NF-kB - nuclear factor kappa B) [18]. Among phenol-carboxylic acids, similar actions are attributed to rosmarinic acid [37]. The anti-inflammatory action of rosmarinic acid can be explained by the inhibition of cyclooxygenase 2 (COX-2) [24]. Rosmarinic acid has an effect against inflammatory and oxidative markers: NO, IL-1ß, MMP2 (nitric oxide, interleukin$1 \beta$ and matrix metallopeptidase 2) being useful for modulating lesions associated with inflammation $[35,44]$. According to the literature, rosmarinic acid has a gastro-protective effect by increasing the production of mucus, by suppressing the activity of neutrophils and pro-inflammatory cytokines. Although, rosmarinic acid has many pharmacological actions, little is known about its bioavailability. Studies indicate that, after oral administration, rosmarinic acid is found in plasma and urine as conjugates [7, 42, 43].

Among the flavonoids, the most studied concerning the mechanism of action are quercetol and its glycosides (rutoside, quercitrin), which are present in the polyphenolic complex of Prunellae spica, according to our determinations. Even if the flavonic glycosides are more hydrophilic than their aglycones, their absorption is better and food supplementation with quercetol leads to plasma concentrations of the order of $\mu \mathrm{mol} / \mathrm{L}$ (this fact shows the difference between nutritional intake and therapeutic supplementation $[11,18]$. Of the quercetol glycosides, quercetin-3-O- $\beta$-D-glucuronopyranoside has been shown to have a dose-dependent protective effect in the indomethacin-induced ulcer model [34], this effect was later confirmed by AbdelRaheem IT for the rutoside [1]. The mechanism of anti-inflammatory action is closely linked to antioxidant action; flavonoids act as scavengers of reactive oxygen species (superoxide anion, nitric oxide, peroxynitrite) involved in the radical mechanism of genesis of inflammatory phenomena and increased levels of inflammatory cytokines, in particular of the tumour necrosis factor alpha (TNF $\alpha)$ [11].

Kim YS et al. used the various agents inducing ulcers ethanol/hydrochloric acid, NSAIDs, acute stress (water immersion-restraint stress-induced gastric lesion) to 
elucidate the effect of phenols of plant origin (paeoniflorin, albiflorin and paeonol). The authors concluded that plant phenolic compounds work primarily by increasing the secretion of prostaglandin-related mucus formation as the first line of defence, in the absence of a consistent anti-secretory effect, as in our case [28]. The involvement of prostaglandins as substances promoting mucus formation was highlighted by these authors by assessment of the reduction in death induced by indomethacin in AGS cells (human epithelial gastric cell line); at the same time, a gastroprotective effect dependent on endogenous sulfhydryl groups was observed, but independent of the formation of nitric oxide (NO) via NO-synthetase, a mechanism attributed to plant polyphenols by other researchers [18]. The cytoprotective mechanism involving the formation of prostaglandins was previously highlighted by Batista LM et al. They attributed the obtained effect to the luteolin content of Signonanthus arthrotrichus [10].

The hydroalcoholic extracts of the Prunella vulgaris L. species are an important source of flavonoids with an antioxidant and cytoprotective action on the gastric mucosa. In addition to increasing gastric microcirculation, activation of NO-synthetase and production of prostaglandins, some authors attribute cytoprotection to an antisecretory mechanism based on flavonoids (inhibition of histidine decarboxylase and consequent decrease in secretion of histamine) $[18,56]$. Other authors (Drăgoi CM et al.) in an experimental model of contact hypersensivity induced by 2,4-dinitrofluorobenzene (DNFB) in BALB/c mice find that the polyphenols of Morus alba reduce the levels of histamine in treated animals [14], decreased histamine synthesis may be a likely mechanism of action. However, our study did not show a significant decrease in titratable acidity. The increase in the defence capacity against hydrochloropeptic aggression following the promotion of prostaglandin synthesis by plant polyphenols was the reason why the preventive effect of the extracts was studied over 4 weeks. Moreover, the experimental model used a nonsteroidal anti-inflammatory drug whose mechanism of action interferes precisely with this type of ulcer. The same timespan was used to assess the curative potential of the studied extracts. In this case, the inhibition of oxidative stress and inflammation, as well as the ability to re-epithelialize are more important than the amount of protective mucus, the formation of which is prostaglandin dependent.

Evidence on the protective mechanisms of phytocompounds on ulcerative lesions has been provided by De Araújo R et al. by immune-histochemical determinations; thus, ethanol, or NSAIDs-induced ulcers are characterized by increased expression in the gastric mucosa of the nuclear factor kappa B-p65
(NF-kB-p65) and of nitric oxide synthase inducible in response to aggression (iNOS); the severity of the lesion can be quantified using as a marker protein ZO-1 (Zone Occludes-1) characteristic of the tight junctions of the intact epithelium; the efficacy of the treatment is correlated with the tissue level of the up-regulation of ZO-1 and of the down-regulation of iNOS and NF-kB-p65; the authors also describe reduced levels of tumour necrosis factor, and of proinflammatory cytokines - TNF $\alpha$, and interleukin $1 \beta$ (IL-1 $\beta$ ) [13], data are also confirmed by Zaghlool SS et al. and Carrasco-Pozo C et al. [12, 55]. Mechanisms of action attributed to polyphenols in gastric ulcer lesions are presented in Figure 5.

Regarding the microscopic features, Simões et al. highlight the observable differences between the ethanol/HCl-induced ulcer model and that using indomethacin. In the first case, the aggressive action is more brutal and non-specific, manifested mainly by haemorrhage; in the second case, inflammation is predominant [49]. The model we chose (phenylbutazoneinduced ulcer) is similar in terms of mechanism to the indomethacin model, and our results are alike (reduction in erosion and inflammation, regeneration of the surface tissue layer). The ethanol-induced ulcer model (used by most authors to study the preventive effect of plant extracts, administered before the induction of the ulcer) $[40,47]$ is mainly characterized by desquamation, severe and marked erosion of the epithelial surface, vacuolation and necrosis, a disorderly and loose arrangement of the epithelial cells, as well as infiltrates of neutrophils/eosinophils [21, 29]. The same types of lesions are present in the case of ulcers induced by NSAIDs, but the phenomena are more discreet and regeneration is faster [27, 45]. The histological features, emphasized by the present study, showed that the hydroalcoholic extract of Prunella vulgaris $\mathrm{L}$ can be successfully utilized as a gastric mucosa protector, but the therapeutic doses and the time of administration, after a diagnosis of peptic ulcer, should be carefully evaluated. Although mucosa regeneration can occur, long-time use can induce dysplasia, with further risk for transformation in adenocarcinoma. However, in the case of proton pump inhibitors - PPIs (e.g. lansoprazole), largely used as antiulcer drugs, histological changes (intestinal metaplasia in rats) have been described. In addition, carcinogenicity studies have shown that all PPIs can induce, in the long term, dose-related gastric ECL cell hyperplasia and ECL cell carcinoids associated with hypergastrinaemia due to inhibition of acid secretion. In the summary of the product characteristics associated with the marketing authorization, the European Medicines Agency (EMA) emphasizes that "the clinical relevance of these findings is unknown" [57]. 


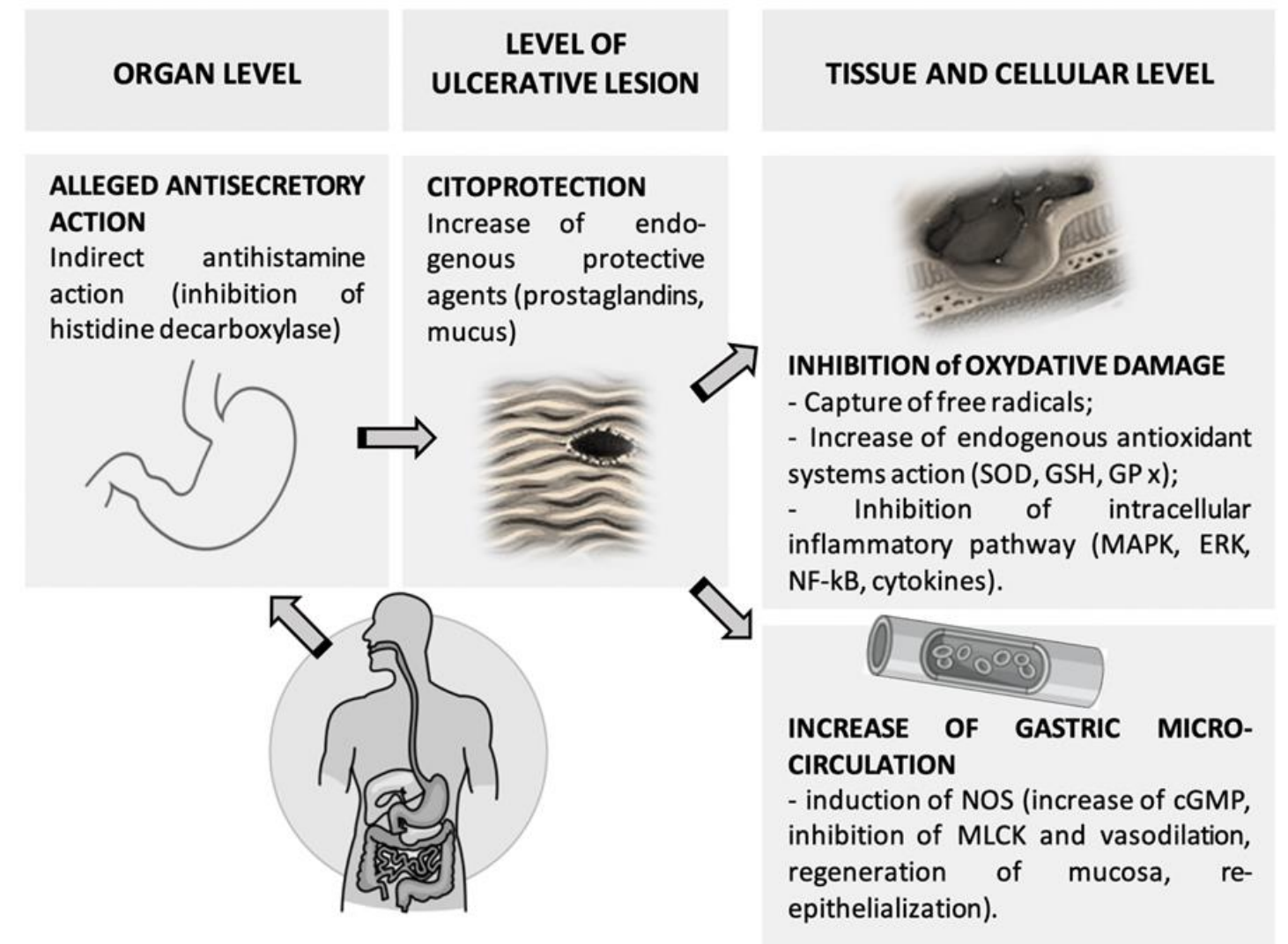

Figure 5.

Mechanisms of action attributed to polyphenols in gastric ulcer lesions

The hydroalcoholic extract can be used as an adjunct to prevent ulcer disease without risk of dysplasia. In the presence of the ulcerative niche, the curative effect, although present, can favour the dysplasia of the mucosa in the regeneration process. We consider that dysplasia after Prunellae spica extract administration to rats is an important signal that this kind of experiments should be repeated on other species. Prunellae spica is an officinal drug in $10^{\text {th }}$ European Pharmacopoeia and is widely used in traditional Asian medicine, especially in China. Thus, we consider that our histological findings are important, although "clinical relevance of these findings is unknown" as EMA stated about PPIs.

\section{Conclusions}

The present study highlights the potential of the hydroalcoholic extract of Prunella vulgaris $L$. to be used as anti-ulcer agent; however, its preventive effect is rather modest, whereas the curative one, although present, may be unsafe because it may lead to dysplasia. However, clinical relevance of these findings is unknown. Demonstrated by reducing the surface area and thickness of the ulcerative lesion, the antiulcerative effect is correlated with the polyphenol content and is not mediated by an antisecretory mechanism.

\section{Conflict of interest}

The authors declare no conflict of interest.

\section{References}

1. Abdel-Raheem IT, Gastroprotective effect of rutin against indomethacin-induced ulcers in rats. Basic Clin Pharmacol Toxicol., 2010; 107(3): 742-750.

2. Abdykerimova S, Sakipova Z, Nakonieczna S, Koch W, Biernasiuk A, Grabarska A, Malm A, Kozhanova K, Kukula- Koch W, Superior antioxidant capacity of Berberis iliensis-HPLC-Q-TOF-MS based phytochemical studies and spectrophotometric determinations. Antioxidants, 2020; 9(6): 1-19.

3. Alkushi AGR, Elsawy NAM, Quercetin attenuates, indomethacin-induced acute gastric ulcer in rats. Folia Morphol (Warsz), 2017; 76(2): 252-261.

4. Asai M, Kawashima D, Katagiri K, Takeuchi R, Tohnai G, Ohtsuka K, Protective effect of a molecular chaperone inducer, paeoniflorin, on the $\mathrm{HCl}$-and ethanol-triggered gastric mucosal injury. Life Sci., 2011; 88(7-8): 350-357.

5. Astudillo L, Rodriguez JA, Schmeda-Hirschmann G, Gastroprotective activity of oleanolic acid derivatives on experimentally induced gastric lesions in rats and mice. J Pharm Pharmacol., 2002; 54(4): 583-588.

6. Ba Y, Wang Y, Content determination in Prunella vulgaris $\mathrm{L}$. and its anti-proliferative effect on thyroid cancer cells. Biomed Res., 2017; 28(8): 3427-3432.

7. Baba S, Osakabe N, Natsume M, Terao J, Orally administered rosmarinic acid is present as the conjugated and/or methylated forms in plasma, and is degraded 
and metabolized to conjugated forms of caffeic acid, ferulic acid and m-coumaric acid. Life Sci., 2004; 75(2): 165-178.

8. Babotă M, Mocan A, Vlase L, Crișan O, Ielciu I, Gheldiu AM, Vodnar DC, Crișan G, Păltinean R, Phytochemical analysis, antioxidant and antimicrobial activities of Helichrysum arenarium (L.) Moench. and Antennaria dioica (L.) Gaertn. Flowers. Molecules, 2018; 23(2): 1-15.

9. Bagheri SM, Zare-Mohazabieh F, Momeni-Asl H, Yadegari M, Mirjalili A, Anvari M, Antiulcer and hepatoprotective effects of aqueous extract of Plantago ovata seed on indomethacin-ulcerated rats. Biomed J., 2018; 41(1): 41-45.

10. Batista LM, De Almeida ABA, de Pietro Magri L, Toma W, Calvo TR, Vilegas W, Brito ARMS, Gastric antiulcer activity of Syngonanthus arthrotrichus Silveira. Biol Pharm Bull., 2004; 27(3): 328-332.

11. Boots AW, Haenen GRMM, Bast A, Health effects of quercetin: from antioxidant to nutraceutical. Eur J Pharmacol., 2008; 585(2-3): 325-337.

12. Carrasco-Pozo C, Morales P, Gotteland M, Polyphenols protect the epithelial barrier function of Caco-2 cells exposed to indomethacin through the modulation of occludin and zonula occludens-1 expression. J Agric Food Chem., 2013; 61(22): 5291-5297.

13. De Araújo ERD, Guerra GCB, Araújo DF de S, De Araújo AA, Fernandes JM, de Araújo Júnior RF, Da Silva VC, De Carvalho TG, Ferreira L, Zucolotto SM, Gastroprotective and antioxidant activity of Kalanchoe brasiliensis and Kalanchoe pinnata leaf juices against indomethacin and ethanol-induced gastric lesions in rats. Int J Mol Sci., 2018; 19(5): 1-25.

14. Drăgoi CM, Olaru OT, Dinu M, Popescu C, Arsene AL, Dune A, Nicolae AC, Ancuceanu RV, Zbârcea CE, Negreș S, Nițulescu GM, Șeremet OC, Characterisation, pharmacotoxicological and biochemical studies on Morus alba L. extract and its fractions. Farmacia, 2018; 66 (1): 120-128.

15. European Pharmacopoeia. $10^{\text {th }}$ ed. www.EDQM.eu. European Directorate for the Quality of Medicines \& HealthCare (EDQM); 2020. 1401-1403.

16. Fahmy NM, Al-Sayed E, Michel HE, El-Shazly M, Singab ANB, Gastroprotective effects of Erythrina speciosa (Fabaceae) leaves cultivated in Egypt against ethanol-induced gastric ulcer in rats. J Ethnopharmacol., 2020; 248: 112297.

17. Faisy C, Guerot E, Diehl JL, Iftimovici E, Fagon JY, Clinically significant gastrointestinal bleeding in critically ill patients with and without stress-ulcer prophylaxis. Intensive Care Med., 2003; 29(8): 13061313.

18. Farzaei MH, Abdollahi M, Rahimi R, Role of dietary polyphenols in the management of peptic ulcer. World J Gastroenterol WJG., 2015; 21(21): 1-20.

19. Danciu C, Pinzaru I, Coricovac D, Andrica F, Sizemore I, Dehelean C, Baderca F, Lazureanu V, Soica C, Mioc M, Radeke H, Betulin silver nanoparticles qualify as efficient antimelanoma agents in in vitro and in vivo studies. Eur J Pharm Biopharm., 2019; 134: 1-19.

20. Golembiovska OI, Simultaneous determination of flavonoids and phenolic acids in different parts of Prunella vulgaris L. by high-performance liquid chromatography with photodiode array detection. Int J Pharmacog Phytochem., 2014; 29(1): 12481255.

21. Guzmán-Gómez O, García-Rodríguez RV, QuevedoCorona L, Pérez-Pastén-Borja R, Rivero-Ramírez NL, Ríos-Castro E, Perez- Gutierrez S, Perez- Ramos J, Chamorro- Cevallos GA, Amelioration of ethanolinduced gastric ulcers in rats pretreated with phycobiliproteins of Arthrospira (Spirulina) maxima. Nutrients., 2018; 10(6): 1-5.

22. Hamedi A, Rezaei H, Azarpira N, Jafarpour M, Ahmadi F. Effects of Malva sylvestris and its isolated polysaccharide on experimental ulcerative colitis in rats. J Evid Based Complementary Altern Med., 2016; 21(1): 14-22.

23. Hanganu D, Olah NK, Pop CE, Vlase L, Oniga I, Ciocarlan N, Matei A, Pușcaș C, Silaghi-Dumitrescu $\mathrm{R}$, Benedec D, Evaluation of some polyphenolic profile and antioxidant activity for some Salvia species. Farmacia, 2019; 67(5): 801-805.

24. Huang N, Hauck C, Yum MY, Rizshsky L, McCoy JA, Murphy PA, Dixon PM, Nikolau BJ, Birt DF, Rosmarinic acid in Prunella vulgaris ethanol extract inhibits lipopolysaccharide-induced prostaglandin E2 and nitric oxide in RAW 264.7 mouse macrophages. J Agric Food Chem., 2009; 57(22): 10579-10589.

25. Iqbal S, Hassan S, Hassan A, Ali M, Nazim U, Zaheer E, Ahmed A, Hussain K, In vitro Spectroscopic studies on drug interaction of cefpodoxime proxetil and $\mathrm{H} 2$ receptor blockers. Pak J Pharm Sci., 2019; 32(2Suppl.): 881-887.

26. Kamiya C, Inui N, Hakamata A, Miyakawa S, Tanaka S, Uchida S, Namiki N, Odagiri K, Watanabe H, Effect of co-administered inducer or inhibitor on omeprazole pharmacokinetics based on CYP2C19 genotype. J Pharmacol Sci., 2019; 139(4): 361-366.

27. Kangwan N, Pintha K, Lekawanvijit S, Suttajit M, Rosmarinic acid enriched fraction from Perilla frutescens leaves strongly protects indomethacin-induced gastric ulcer in rats. Biomed Res Int., 2019; 2019: 1-13.

28. Kim YS, Park HJ, Kim H, Song J, Lee D, Gastroprotective effects of Paeonia extract mixture HT074 against experimental gastric ulcers in rats. Evidence-Based Complement Altern Med., 2019; 2019: 1-13.

29. Li J, Wang T, Zhu Z, Yang F, Cao L, Gao J, Structure features and anti-gastric ulcer effects of inulin-type fructan CP-A from the roots of Codonopsis pinosula (Franch). Nannf. Molecules, 2017; 22(12): 1-11.

30. Liu J, Feng L, Gu J, Wang R, Zhang M, Jiang J, Qin D, Jia X, Chen Y, Chen S, Simultaneous determination of ten characteristic antioxidant compounds for inhibiting cancer cell proliferation in Prunella vulgaris L. from different regions using HPLC-UV coupled with MS identification. Anal Methods, 2014; 6(9): 3139-3146.

31. Liu ZX, Hua YJ, Wang SN, Zou LS, Liu XH, Zhao H, Yan Y, Quality evaluation of Prunellae spica based on simultaneous determination of multiple bioactive constituents combined with grey relational analysis. Nat Prod Commun., 2017; 12(7): 1-5.

32. Ma X, Lu G, Song S, Liu W, Wen Z, Zheng X, Lu $\mathrm{Q}, \mathrm{Su} \mathrm{D}$, The features of reserpine-induced gastric mucosal lesions. Acta Pharmacol Sin., 2010; 31(8): 938-943. 
33. Meda RNT, Vlase L, Lamien-Meda A, Lamien CE, Muntean D, Tiperciuc B, Oniga I, Nacoulma O, Identification and quantification of phenolic compounds from Balanites aegyptiaca (L) Del (Balanitaceae) galls and leaves by HPLC-MS. Nat Prod Res., 2011;25(2): 93-99.

34. Min YS, Lee SE, Hong ST, Kim HS, Choi BC, Sim SS, Whang WK, Sohn UD, The inhibitory effect of quercetin-3-o- $\beta$-d-glucuronopyranoside on gastritis and reflux esophagitis in rats. Korean J Physiol Pharmacol., 2009; 13(4): 295-300.

35. Mocan A, Vlase L, Raita O, Hanganu D, Păltinean R, Dezsi Ş, Gheldiu AM, Oprean R, Crişan G, Comparative studies on antioxidant activity and polyphenolic content of Lycium barbarum L. and Lycium chinense Mill, leaves. Pak J Pharm Sci., 2015; 28(4 Suppl): 1511-1515.

36. Mousa AM, El-Sammad NM, Hassan SK, Abd El Nasser AM, Hashim AN, Moustafa ES, Bakry SM, Elsayed EA, Antiulcerogenic effect of Cuphea ignea extract against ethanol-induced gastric ulcer in rats. BMC Complement Altern Med., 2019; 19(1): 1-13.

37. Nadeem M, Imran M, Aslam Gondal T, Imran A, Shahbaz M, Muhammad AR, Wasim Sajid M, Batool Qaisrani T, Atif M, Hussain G, Therapeutic potential of rosmarinic acid: A comprehensive review. Appl Sci., 2019; 9(15): 1-23.

38. Ogasawara O, Kojima T, Miyazu M, Sobue K, Impact of the stress ulcer prophylactic protocol on reducing the unnecessary administration of stress ulcer medications and gastrointestinal bleeding: a single-center, retrospective pre-post study. J Intensive Care., 2020; 8(1): 1-9.

39. Onwuchekwa C, Oluwole FS, Anti-gastric ulcer and antiinflammatory properties of betulinic acid in male albino rats. Sci World J., 2010; 5(4): 15-17.

40. Pandey D, Joshi A, Hemalatha S, Anti-ulcer study of standardized ethanol root extract of Aganosma dichotoma and isolated ursolic acid. Int J Pharm Pharm Sci., 2017; 9: 172-180.

41. Pop CE, Parvu M, Arsene AL, Parvu AE, Vodnar DC, Tarcea M, Toiu AM, Vlase L, Investigation of antioxidant and antimicrobial potential of some extracts from Hedera helix L. Farmacia, 2017; 65(4): 624-629.

42. Psotova J, Svobodova A, Kolarova H, Walterova D, Photoprotective properties of Prunella vulgaris and rosmarinic acid on human keratinocytes. J Photochem Photobiol B Biol., 2006; 84(3): 167-174.

43. Rahbardar MG, Amin B, Mehri S, Mirnajafi-Zadeh SJ, Hosseinzadeh H, Anti-inflammatory effects of ethanolic extract of Rosmarinus officinalis L. and rosmarinic acid in a rat model of neuropathic pain. Biomed Pharmacother., 2017; 86: 441-449.

44. Rocha J, Eduardo-Figueira M, Barateiro A, Fernandes A, Brites D, Bronze R, Duarte CM, Serra AT, Pinto R, Freitas M, Anti-inflammatory effect of rosmarinic acid and an extract of Rosmarinus officinalis in rat models of local and systemic inflammation. Basic Clin Pharmacol Toxicol., 2015; 116(5): 398-413.
45. Sabiu S, Garuba T, Sunmonu T, Ajani E, Sulyman A, Nurain I, Balogun A, Indomethacin-induced gastric ulceration in rats: protective roles of Spondias mombin and Ficus exasperata. Toxicol Rep., 2015; 2: 261-267.

46. Sánchez M, Theoduloz C, Schmeda-Hirschmann G, Razmilic I, Yáñez T, Rodríguez JA, Gastroprotective and ulcer-healing activity of oleanolic acid derivatives: in vitro-in vivo relationships. Life Sci., 2006; 79(14): 1349-1356.

47. Sattar A, Abdo A, Mushtaq MN, Anjum I, Anjum A, Evaluation of gastro-protective activity of Myristica fragrans on ethanol-induced ulcer in albino rats. $A n$ Acad Bras Cienc., 2019; 91(2): 1-8.

48. Shimamoto T, Yamamichi N, Kodashima S, Takahashi Y, Fujishiro M, Oka M, Mitsushima T, Koike K, No association of coffee consumption with gastric ulcer, duodenal ulcer, reflux esophagitis, and non-erosive reflux disease: a cross-sectional study of 8,013 healthy subjects in Japan. PLoS One., 2013; 8(6): 1-9.

49. Simões S, Lopes R, Campos MCD, Marruz MJ, da Cruz MEM, Corvo L, Animal models of acute gastric mucosal injury: Macroscopic and microscopic evaluation. Anim Model Exp Med., 2019; 2(2): 121-126.

50. Singleton VL, Orthofer R, Lamuela-Raventós RM, Analysis of total phenols and other oxidation substrates and antioxidants by means of Folin-Ciocalteu reagent. Methods Enzymol.,1999; 299: 152-178.

51. Şahin S, Demir C, Malyer H, Determination of phenolic compounds in Prunella L. by liquid chromatographydiode array detection. J Pharm Biomed Anal., 2011; 55(5): 1227-1230.

52. Vema BK, Mukerjee A, Verma A, Bhushan S, Preclinical screening of antiulcer activity of Asparagus racemosus extract on phenylbutazone induced ulceration in experimental animals. J Med Plants., 2017; 5(2): 348-352.

53. Wang SJ, Wang XH, Dai YY, Ma MH, Rahman K, Nian H, Zhang H, Prunella vulgaris: A comprehensive review of chemical constituents, pharmacological effects and clinical applications. Curr Pharm Des., 2019; 25(3): 359-369.

54. Yang A, Zheng Z, Liu F, Liu J, Wang R, Yang H, Huang Z, Huang P, Liu H, Screening for potential antibreast cancer components from Prunellae spica using MCF-7 cell extraction coupled with HPLCESI-MS/MS. Nat Prod Commun., 2020;15(6): 1-5.

55. Zaghlool SS, Abo-Seif AA, Rabeh MA, Abdelmohsen UR, Messiha BAS, Gastro-protective and anti-oxidant potential of Althaea officinalis and Solanum nigrum on pyloric ligation/indomethacin-induced ulceration in rats. Antioxidants. 2019; 8(11): 1-31.

56. Zayachkivska OS, Konturek SJ, Drozdowicz D, Konturek PC, Brzozowski T, Ghegotsky MR, Gastroprotective effects of flavonoids in plant extracts. J Physiol Pharmacol Suppl., 2005; 56(1): 219-231.

57. www.ema.europa.eu. 